\title{
Towards manufactured red blood cells for the treatment of inherited anemia
}

\author{
Stephanie Pellegrin, ${ }^{1,2}$ Charlotte E. Severn ${ }^{1,2}$ and Ashley M. Toye ${ }^{1,2,3}$
}

${ }^{1}$ School of Biochemistry, Biomedical Sciences Building; ${ }^{2}$ National Institute for Health Research (NIHR) Blood and Transplant Research Unit in Red Blood Cell Products, University of Bristol and ${ }^{3}$ Bristol Institute of Transfusion Sciences, NHSBT Filton, Bristol, UK

Haematologica 2021

Volume 106(9):2304-2311

\section{Correspondence:}

ASHLEY TOYE

ash.m.toye@bristol.ac.uk

Received: February 2, 2021.

Accepted: March 31, 2021.

Pre-published: May 27, 2021.

https://doi.org/10.3324/haematol.2020.268847

(C)2021 Ferrata Storti Foundation

Material published in Haematologica is covered by copyright. All rights are reserved to the Ferrata Storti Foundation. Use of published material is allowed under the following terms and conditions:

https://creativecommons.org/licenses/by-nc/4.0/legalcode. Copies of published material are allowed for personal or internal use. Sharing published material for non-commercial purposes is subject to the following conditions:

https://creativecommons.org/licenses/by-nc/4.0/legalcode, sect. 3. Reproducing and sharing published material for commercial purposes is not allowed without permission in writing from the publisher.

\section{ABSTRACT}

P atients with inherited anemia and hemoglobinopathies (such as sickle cell disease and $\beta$-thalassemia) are treated with red blood cell (RBC) transfusions to alleviate their symptoms. Some of these patients may have rare blood group types or go on to develop alloimmune reactions, which can make it difficult to source compatible blood in the donor population. Laboratory-grown RBC represent a particularly attractive alternative which could satisfy an unmet clinical need. The challenge, however, is to produce - from a limited number of stem cells - the $2 \times 10^{12}$ $\mathrm{RBC}$ required for a standard adult therapeutic dose. Encouraging progress has been made in RBC production from adult stem cells under good manufacturing practice. In 2011, the Douay group conducted a successful proof-of-principle mini-transfusion of autologous manufactured RBC in a single volunteer. In the UK, a trial is planned to assess whether manufactured $\mathrm{RBC}$ are equivalent to $\mathrm{RBC}$ produced naturally in donors, by testing an allogeneic mini-dose of laboratory-grown manufactured $R B C$ in multiple volunteers. This review discusses recent progress in the erythroid culture field as well as opportunities for further scaling up of manufactured $\mathrm{RBC}$ production for transfusion practice.

\section{Introduction}

Red blood cell (RBC) transfusions are the mainstay treatment for anemic patients and are given routinely in hospitals around the world. Depending on the clinical presentation, blood transfusions are likely to be administered to improve the patients' quality of life and are administered either intermittently when needed, or for extended periods, as in the case of $50-90 \%$ of patients suffering from myelodysplastic syndromes and for transfusion-dependent patients with inherited anemia and hemoglobinopathies (such as sickle cell disease and $\beta$-thalassemia). Chronic $\mathrm{RBC}$ transfusions introduce secondary complications which contribute to morbidity, due mainly to transfusion-induced iron overload and erythrocyte alloimmunization. ${ }^{1,2}$ It is particularly challenging for blood services to source RBC compatible for multiply alloimmunized patients with chronic transfusion-dependent anemia or rare blood types. ${ }^{3,4}$

Breakthroughs in the field of erythropoiesis research have led to the development of reproducible protocols that can yield large numbers of cultured human reticulocytes, often referred to as laboratory-grown or cultured red blood cells (cRBC). In addition to being an excellent model system for exploring human erythropoiesis in health and disease, this work has laid the foundations for the interest in producing human cRBC for transfusion purposes or as a vehicle for red cell-based therapeutics. The production of cRBC from stem cells or other cellular sources (see below) may one day fill the unmet clinical need for transfusion-dependent patients, but only if the challenge of growing enough clinical grade RBC can be met.

The term "manufactured RBC" ( $\mathrm{mRBC}$ ) refers to clinical grade cRBC grown under good manufacturing practises (GMP). Both $\mathrm{cRBC}$ and $\mathrm{mRBC}$ are in fact nascent $\mathrm{RBC}$, known as reticulocytes.-7 and they are referred to only as $\mathrm{mRBC}$ within this manuscript from now on to avoid confusion. One added benefit of mRBC, compared to standard donor-derived RBC, is that they are a homogeneous population of immature RBC that should last the normal 120-day lifetime in the circulation. This 
regenerative medicine product is anticipated to reduce transfusion frequency and the associated iron overload. ${ }^{6}$ Support for this idea comes from studies showing that transfusion of young RBC (also called neocytes) is beneficial to patients with inherited anemias, reducing iron overload and increasing the interval between transfusions. ${ }^{8-12}$

$\mathrm{mRBC}$ have been tested in immunocompromised mice models ${ }^{5,6,13}$ and non-human primates. ${ }^{13}$ Importantly, a proof-of-principle mini-transfusion of autologous $\mathrm{mRBC}$ has been conducted in a single volunteer, illustrating that $\mathrm{mRBC}$ can survive in the circulation and are safe for use in humans. ${ }^{5}$ The benefit of $\mathrm{mRBC}$ in allogeneic transfusions across multiple recipients still needs to be demonstrated before moving to patients. The commercial company Rubius Therapeutics has a business model built around producing novel $\mathrm{mRBC}$ for therapeutics. To date, Rubius has conducted one injection of $\mathrm{mRBC}$ engineered for treatment of phenylketonuria in a single patient (Rubius press release $12^{\text {th }}$ March $2020^{14}$ ), but no further specific information was released. In the UK, the National Health Service Blood and Transplant (England's Blood Service) is intending to conduct a single-center, randomized, allogeneic, controlled, phase I, cross-over trial denominated RESTORE (Recovery and Survival of Stem Cell Originated Red Cells (ISRCTN:42886452 and EudraCT: 2017-00217838). This healthy volunteer trial has faced significant delays, most recently due to the COVID-19 pandemic but will, it is hoped, be carried out in the near future to assess the recovery and survival of a mini-dose of $m R B C$ derived from $\mathrm{CD}_{34}{ }^{+}$cells isolated from adult blood donors versus the standard RBC from the same donor.

Laboratory-grown RBC offer the greatest potential in terms of sourcing rare blood groups for sickle cell and thalassemia patients with alloimmunity. It must be acknowledged however, that these patients also present the greatest challenge in terms of requirements for blood. Adult patients require multiple units of blood per month. ${ }^{15}$ Realistically, the first therapeutic use of $\mathrm{mRBC}$ is likely to take place in a pediatric setting or for red cell-based therapeutics, such as enzyme replacement therapies, as both these applications require smaller numbers of $\mathrm{mRBC}$. There is also a need to determine the number of $\mathrm{mRBC}$ that represents a therapeutic dose. For adult patients, one unit of standard RBC is estimated to consist of approximately $2 \times 10^{12} \mathrm{RBC}$ which raises the hemoglobin of an average adult by $1 \mathrm{~g} / \mathrm{dL}$. For pediatric patients, doses are more variable as they depend on the weight of the patient but are lower than an adult dose. It should be noted that a proportion $(5-10 \%)$ of standard RBC are lost within the first 24 hours after transfusion ${ }^{16}$ and this increases to $25 \%$ or more with blood storage time. Therefore, the actual number of $\mathrm{RBC}$ required to treat anemia is likely to be lower if the majority of the cells are nascent.

Many excellent reviews have been written on $\mathrm{mRBC}$ and the prospect of using mRBC for transfusion. ${ }^{17-25} \mathrm{We}$ therefore offer below a concise overview of the progress to date, highlighting the relevant issues and opportunities for optimizing and increasing the $\mathrm{mRBC}$ yield to an adult therapeutic dose.

\section{Overview of the erythroid culture process}

The recapitulation of erythropoiesis using primary hematopoietic stem and progenitor cells (HSPC) ex vivo requires specific combinations of cytokines and growth factors in order to first expand the HSPC, and then to direct lineage specification to ensure full differentiation to the reticulocyte stage (see Figure 1). Over the last 20 years, multiple laboratories have developed two-dimensional liquid culture systems that reproduce the process and stages of human erythropoiesis to generate reticulocytes. These include two to four stages, each characterized by the inclusion or omission of specific growth factors (Table 1). The general consensus is for the inclusion of a primary stage favoring HSPC expansion with interleukin-3 and stem cell factor, a secondary erythroblast expansion stage including stem cell factor and erythropoietin, followed by a terminal differentiation stage with erythropoietin. Notably, holotransferrin is included throughout the culture period. Some laboratories further modify the initialstage culture media by including, for example, thrombopoietin and fms-like tyrosine kinase 3 (Flt-3) to enhance stem cell proliferation ${ }^{13}$ and may also include glucocorticoids to increase expansion prior to differentiation. ${ }^{26}$ The more recent culture protocols listed in Table 1 have been undertaken at considerably larger scale (i.e., at least $1 \mathrm{~L}$ ), with some reports of successful generation of large numbers of reticulocytes. The challenge for the field is to increase the production even further to generate the equivalent of a therapeutically useful adult dose.

\section{Starting material}

The studies reporting the highest yields all use HSPC specifically isolated from cord blood, ${ }^{13,27}$ mobilized $^{5}$ or standard peripheral blood ${ }^{6,28}$ (Table 1). Another option is to use the whole peripheral blood mononuclear cell (PBMNC) component for production of $\mathrm{mRBC}$, thereby omitting the expensive step of $\mathrm{CD}_{3} 4^{+}$isolation. ${ }^{7,29}$ As well as reducing costs, the use of $\mathrm{PBMNC}$ as the starting material under the correct culture conditions can contribute towards increasing the yield of $\mathrm{mRBC}$. Indeed, PBMNC include all cells with erythroid lineage potential, some of which are CD34 that can enhance culture yield. ${ }^{29} \mathrm{PBMNC}$ also include $\mathrm{CD}_{14}{ }^{+}$cells that might act as helper/feeder cells that can limit the cell death of erythroid progenitors during the first few days of culture when volumes are still small and cells are kept in static tissue culture flasks or dishes. ${ }^{30,31}$

We highlight that there are other sources that are gaining traction, including immortalized pluripotent stem cells and immortalized cell lines, ${ }^{32,33}$ which can be used to differentiate to reticulocytes, but we will not discuss these here because these have not yet been grown at scale. These sustainable cellular sources have great potential for continual blood production once the technical challenges of growing them have been circumvented and are likely to comprise a second wave of blood products after stem cellderived $\mathrm{mRBC}$.

\section{Natural donor variation and yields}

The genetic makeup of the donor-derived cellular starting material has long been recognized to have an impact on yield, which is problematic when trying to consistently produce a high number of $\mathrm{mRBC}$ using random donors. ${ }^{34}$ This variation could be due to the number of HSPC pres- 
ent per volume of blood, which is highly variable between donors, or down to subtle variations in genetic factors that influence how HSPC and erythroid progenitors proliferate, enucleate and/or respond to culture media composition. More work is therefore needed to explain the differences in yields observed between donors under standardized and reproducible culture conditions. The payoff from this painstaking work would be the identification of potential genetic variations that could be pre-screened for or utilized by genetically engineering alterations the starting material to benefit production.

Genome-wide association studies as well as identification of rare phenotypes linked to specific RBC traits might help to identify genetic variants suitable for reliably producing large numbers of $\mathrm{mRBC}$. An example of such an approach was carried out by Sankaran's group. ${ }^{35}$ LNK/SH2B3 is an adaptor protein that negatively regulates hematopoietic cytokine signaling. Rare lost-of-function SH2B3 alleles have been associated with JAK2-mutationnegative erythrocytosis ${ }^{36,37}$ and a hypomorphic allele of SH2B3 (single nucleotide polymorphism rs3184504) was found to be significantly associated with high hemoglobin levels, packed cell volume and RBC count in vivo. ${ }^{38}$ Using shRNA knockdown in adult, mobilized, peripheral blood and cord blood CD34+ cells, Giani et al. ${ }^{35}$ suppressed the expression of the LNK/SH2B3 protein and reported a 2- to 7-fold increase in yield of enucleated RBC in shRNA-treated cells compared to cells transduced with a control shRNA. More recently, a study of rare MAM-negative individuals by Thornton and colleagues ${ }^{39}$ showed that peripheral blood $\mathrm{CD} 34^{+}$cells from two MAM-negative individuals had a proliferation advantage in ex-vivo erythroid cultures, resulting in an average 5-fold increase in cell number compared to four age- and gender-matched MAM-positive controls. Whether the same observations concerning loss-of-function $\mathrm{SH} 2 \mathrm{~B} 3$ and MAM-negative cells hold true for large-scale cultures and across multiple donors still needs to be determined.

Beyond yield, the choice of donor can also affect the quality of the final $\mathrm{mRBC}$ product due to the donor's own RBC intrinsic characteristics - not just in terms of blood group which can be selected for, but also in terms of storage characteristics or even longevity in circulation once transfused. The planned RESTORE clinical trial may provide data on this as the survival time of transfused stem cell-derived $\mathrm{mRBC}$ in the circulation of the recipient will be directly compared to the survival time in circulation of the same donor's standard RBC.

\section{Genetic manipulation and small molecules}

A key challenge for the field is to prevent the attrition of the self-renewal capacity of HSPC and to maintain the expansion capacity of erythroid progenitors (burst-forming and colony-forming units-erythroid) for a longer period before terminal erythroid differentiation occurs. One way to do this is through the use of glucocorticoids (see below) which can potentially improve the asynchronicity of enucleation in cultures, and may then improve reticulo-

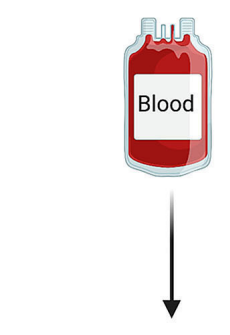

PBMNCs or CD34+
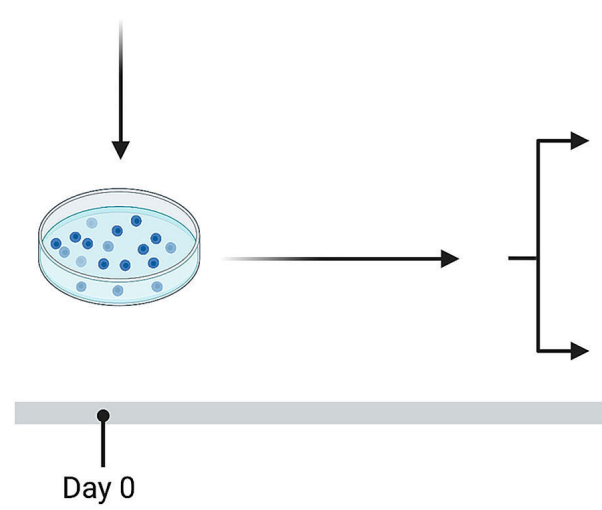
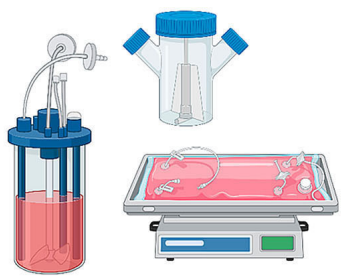

Bioreactors

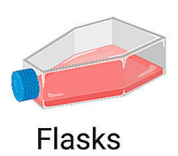

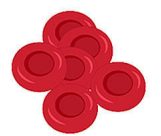

Reticulocytes
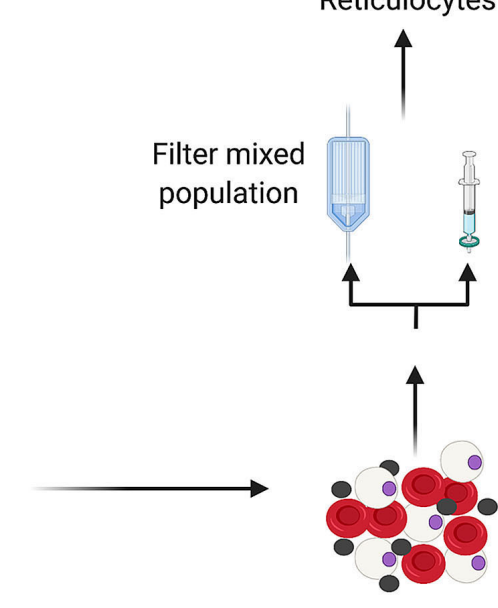

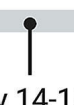

Day $14-15$

Day 7-10

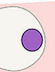

Figure 1. Overview of the erythroid culture process. Ex vivo culture systems require the isolation of peripheral blood mononuclear cells (PBMNC) or magnetic sorting of the CD34+ cells as starting material. Culture systems then employ either flasks, spinner flasks or a bioreactor system depending on scale. The volume of the culture will increase dramatically as the cells expand and differentiate through days 7-14. Upon generation of a mixed population of reticulocytes, nucleated cells and pyrenocytes at day 21 , cells then require filtration using either a syringe (small scale) or multiple leukocyte filters (large scale) depending on volume to give a pure reticulocyte population. Diagram made using biorender.com. 
cyte stability and filtration efficiency. Another way is to use culture manipulation to try and maintain stemness and proliferation potential. For example, there are small molecule inhibitors that are reported to enhance cord blood HSPC self-renewal, such as UM171 ${ }^{40}$ and the aryl hydrocarbon receptor agonist SR-1.11 There are also factors such as angiopoietin-like 5 and IGBFP $2^{42}$ and notch ligand. ${ }^{43}$ Although there is evidence that these small molecules or factors enhance HSPC expansion, there are no data yet to suggest that they can enhance the yield of reticulocytes when cultured on a large scale.

Perhaps the most exciting advancement in erythroid progenitor manipulation is the recently reported overexpression of BMI1 in human HSPC, which gave a $10^{12}$ fold increase of erythroblasts. ${ }^{44}$ Not only does the extensive expansion give the potential for higher yields (assuming the cells do not differentiate spontaneously when grown in large volumes), it also confers the opportunity for further genetic manipulation due to the extended time frame. Genetic manipulation in the form of YTHDF2 knockdown also generated a reported 14.3-fold increase in CD34+ frequency in the culture conditions used by a separate group of researchers. ${ }^{45}$ Alternatively, better biomimicry of the stem cell niche to recapitulate conditions ex vivo has the potential to maintain HSPC stemness for longer periods and therefore increase yield; however, these technologies still require further development. ${ }^{46.52}$ It will be very interesting to see if applications of these innovations can translate into higher yields for large-scale mRBC production.

\section{Media composition and optimization}

As well as exploiting cell-intrinsic properties, the base medium composition could be further developed and supplemented. Erythroid progenitors are generally cultured in Iscove modified Dulbecco medium (IMDM) and laborato- ries maintain consistency with suppliers whenever possible. There are many different IMDM commercially available, some better than others in terms of supporting the proliferation and enucleation of erythroid progenitors. Studies are needed to determine exactly what nutrients are required to support the highest proliferation rates of HSPC and erythroid progenitors in culture, particularly important when culturing at high cell densities. Interestingly Heshusius et al. supplemented their IMDM with nucleosides and a range of trace elements to make a more defined GMP-compliant medium. Zhang and colleagues ${ }^{13}$ added folic acid and selenium to their large-scale cultures of human cord blood $\mathrm{CD} 34^{+}$cells. An experimental approach, using parallel stirred tank micro-bioreactors, is needed to identify the definitive media and supplements to use for erythroid culture.

The lipid sources added to base media by different laboratories also vary significantly, with some groups favoring different amounts of plasma, serum (human or bovine) or serum-free conditions supplemented with animal, human or plant-derived lipid-rich reagents. For compliance with GMP, animal sources must eventually be substituted, which can have an impact on yields. In their recent report Heshuvius et al. also highlighted the importance of albumin purity for proliferation.? Interestingly, Wilkinson et al. ${ }^{53}$ showed that $0.1 \%$ human serum albumin can be replaced by $0.1 \%$ polyvinyl alcohol for cultures of human umbilical cord blood-derived CD34+ cells but as yet this observation has not been tested on a large scale.

\section{Glucocorticoids}

The importance of glucocorticoids in promoting stress erythropoiesis was originally discovered in avian and mice studies $s^{54,55}$ and glucocorticoids have been used to increase the yield of human mRBC. . $6,29,56,57^{2}$ Three of the larger-scale

Table 1. Summary of recently published, large-scale erythroid culture systems, with expansion and enucleation rates where provided as well as bioreactor and GMP/non-GMP media constituents where applicable. Exhaustive reviews of small-scale erythroid cultures can be found elsewhere..$^{20,22,25}$

\begin{tabular}{|c|c|c|c|c|c|}
\hline Source and culture period & General protocol & Expansion & Enucleation rate & Key points & Reference \\
\hline $\begin{array}{l}\text { Cord blood, } \\
33 \text { days }\end{array}$ & Two-stage & $\begin{array}{c}2.3 \times 10^{8} \\
\text { by extrapolation }\end{array}$ & $>90 \%$ & $\begin{array}{l}\text { First demonstration of bioreactor use; } \\
1 \text { L cultures in wave-type bioreactor; } \\
\text { non-GMP (use of BSA) }\end{array}$ & Timmins et al., 2011 \\
\hline $\begin{array}{l}\text { Peripheral blood } \\
\text { CD } 34^{+} \text {cells }\end{array}$ & Three-stage & $\begin{array}{l}6.15 \times 10^{4} \text { fold } \\
\text { Large cultures } \\
\text { (actual yield) }\end{array}$ & $68 \%$ & $\begin{array}{l}1 \text { culture of } 2.5 \mathrm{~mL} \text { packed filtered } \\
\text { mRBC under GMP conditions } \\
\text { autologous human transfusion }\end{array}$ & Giarratana et al., 2011 \\
\hline $\begin{array}{l}\text { Peripheral blood } \\
\text { CD } 34^{+} \text {cells, } \\
20 \text { days }\end{array}$ & Three-stage & $\begin{array}{l}\quad>10^{4} \text { fold } \\
\text { Large cultures } \\
\text { (actual yield) }\end{array}$ & $55-95 \%$ & $\begin{array}{l}5 \mathrm{~mL} \text { packed filtered mRBC, } \\
\text { constant batch feeding in spinner } \\
\text { flasks (no medium changes); } \\
\text { non GMP }\end{array}$ & Griffiths et al., 2012 \\
\hline $\begin{array}{l}\text { Peripheral blood and } \\
\text { cord blood CD } 34^{+} \text {cells } \\
20 \text { days }\end{array}$ & Three-stage & $\begin{array}{l}>10^{5} \text { fold } \\
\text { Large cultures } \\
\text { (actual yield) }\end{array}$ & c & $\begin{array}{c}\text { Large scale cultures }(\sim 25 \mathrm{~L}) \\
10 \mathrm{~mL} \text { packed filtered mRBC using } \\
\text { constant batch feeding in spinner flasks under } \\
\text { GMP conditions }\end{array}$ & Kupzig et al., 2017 \\
\hline $\begin{array}{l}\text { Cord blood } \\
\text { CD34+ cells }\end{array}$ & Four-stage & $\begin{array}{l}2.9 \times 10^{5} \text { fold } \\
\text { Large cultures } \\
\text { (actual yield) }\end{array}$ & & $\begin{array}{l}\text { Large scale culture in rotating wall vessels; } \\
\text { non-GMP (use of } 15 \% \text { FBS } \\
\text { in steps } 2 \& 3 \text { ) }\end{array}$ & Zhang et al., 2017 \\
\hline $\begin{array}{l}\text { Peripheral blood MNC } \\
\text { (no CD34+ cell isolation) } \\
21 \text { to } 37 \text { days } \\
\text { (due to expansion stage) }\end{array}$ & Three-stage & $\begin{array}{c}10^{7} \text { fold } \\
\text { by extrapolation }\end{array}$ & $>90 \%$ & $\begin{array}{l}\text { G-Rex bioreactor } \\
\text { GMP compliant: serum-free and plant } \\
\text { derived lipids for expansion; } \\
\text { 5\% human plasma for differentiation }\end{array}$ & Heshusius et al., 2019 \\
\hline
\end{tabular}

GMP: Good Manufacturing Practice; BSA: bovine serum albumin, mRBC: manufactured red blood cells, FBS: fetal bovine serum; MNC: mononuclear cells. 
erythroid culture protocols reported to date incorporate glucocorticoids, using either dexamethasone in serum-free conditions ${ }^{7}$ or hydrocortisone in the presence of $5 \%$ plas$\mathrm{ma}^{5}$ or in serum-free conditions. ${ }^{27}$

Recent studies have highlighted both the importance of lipid metabolism during terminal erythroid differentiation ${ }^{58}$ and the fact that exposure to glucocorticoids can affect the lipid metabolism in cultured erythroid cells. ${ }^{59,60}$ For erythroid cells cultured in the presence of hydrocortisone, the defect in lipid metabolism and resulting fragility of $\mathrm{mRBC}$ can be counteracted by supplementing the medium with cholesterol-rich lipids. ${ }^{60}$ Interestingly though, addition of cholesterol-rich lipids slightly accelerated differentiation ${ }^{60}$ and Heshuvius et al. reported that the addition of plasma caused premature differentiation in the presence of dexamethasone. The interplay between glucocorticoid exposure time and lipid metabolism needs further investigation to maximize yield without compromising $\mathrm{mRBC}$ quality.

Table 2. Highlighted strategies to improve current culture systems for manufactured red blood cells.

\begin{tabular}{|c|c|}
\hline Starting material & $\begin{array}{l}\text { - selection of donors with genetic markers linked to specific RBC traits (high hemoglobin, packed } \\
\text { cell volume or RBC count) } \\
\text { - selection of donors with consistently high HSPC counts } \\
\text { - use of whole mononuclear cell population (PBMNC) not just CD34+ cells } \\
\text { - genetic manipulation of starting material to enhance proliferation and compatibility }\end{array}$ \\
\hline Media composition and supplements & $\begin{array}{l}\text { - slow down attrition of HSPC self-renewal capacity } \\
\text { - maximize expansion of erythroid progenitors (CFU-E) } \\
\text { - maximize enucleation and maintain nascent reticulocyte viability }\end{array}$ \\
\hline Filtration & $\begin{array}{l}\text { - novel filtration technology to minimize loss of mRBC } \\
\text { - maturation of mRBC to erythrocytes will enhance filtration efficiency }\end{array}$ \\
\hline Storage & $\begin{array}{l}\text { - optimal reticulocyte storage conditions to minimize loss of filtered mRBC until transfusion } \\
\text { - maturation of mRBC to erythrocytes to enhance storage times }\end{array}$ \\
\hline GMP-compliance and reproduchilility & \\
\hline Starting material & • minimize stem cell donor variability and cell loss during isolation \\
\hline Media composition and supplements & $\begin{array}{l}\text { - use defined reagents of known reliability and controlled provenance } \\
\text { - multiple suppliers identified for key reagents } \\
\text { - supplier surveys and site visits }\end{array}$ \\
\hline Bioreactors and filtration & $\begin{array}{l}\text { - closed systems } \\
\text { - scalable GMP-compliant bioreactors with ease of use } \\
\text { - close monitoring of the culture growth } \\
\text { - GMP-compliant filtration process }\end{array}$ \\
\hline
\end{tabular}

\begin{tabular}{ll}
\hline Other considerations & $\bullet$ define release criteria of product and storage times \\
& $\bullet$ identification of optimum therapeutic dose of mRBC
\end{tabular}

\section{Cost reduction}

Starting material

Media composition and supplements
- use of PBMNC to circumvent expensive CD34+ cell isolation

- defined in-house media constituents

- in-house growth factors

- replace or reduce the most expensive constituents (e.g. holotransferrin)

- develop protocols/bioreactors that use less medium overall without affecting the yield and quality of $\mathrm{mRBC}$ obtained

- enhance media to enable increases in cell density

Bioreactors and filtration $\quad \begin{array}{ll}\bullet & \text { fully automated culture processes } \\ & \text { - automated filtration } \\ & \text { minimal footprint and labor requirement }\end{array}$

RBC: red blood cells; mRBC: manufactured RBC; HSPC: hematopoietic stem and progenitor cells; PBMNC: peripheral blood mononuclear cells; CFU-E: colony-forming unit erythroid; GMP: Good Manufacturing Practice. 


\section{Holotransferrin}

The majority of current protocols use between 0.33 and $0.7 \mathrm{mg} / \mathrm{mL}$ holotransferrin isolated from human plasma, ${ }^{5.7}$ which represents the highest costing individual culture reagent. Holotransferrin is the natural carrier used to deliver iron to the developing erythroid cell by binding to CD71 and being internalized. It is then recycled by the cell and released back into the medium in its apo-form. A cheaper, plant-derived recombinant holotransferrin, optiferrin, is available but this is still expensive. Theoretically, the transferrin concentration could be reduced in culture media as long as iron is also supplemented to bind apo-transferrin, without causing cell toxicity or increasing the likelihood of bacterial growth. For example, Timmins and colleagues used $0.12 \mathrm{mg} / \mathrm{mL}$ holotransferrin in combination with 900 $\mathrm{ng} / \mathrm{mL}$ ferrous sulfate and $90 \mathrm{ng} / \mathrm{mL}$ ferric nitrate..$^{27}$ Olivier et al. used holotransferrin at a concentration of $0.05 \mathrm{mg} / \mathrm{mL}$ and $3 \mathrm{mM}$ FeIII-EDTA in small scale immortalized pluripotent stem cell cultures, reportedly without affecting the yield of reticulocytes, but the potential impact on mean cell hemoglobin concentrations and viability during storage of the mRBC produced was not measured. ${ }^{61}$ Other iron supplements that could be tested include reagents that would deliver iron to erythroid cells in a CD71-independent manner. These include the small lipophilic molecule hinokitiol that can carry iron across the cell membrane into erythroid cells ${ }^{62,63}$ or alternatively, ferric carboxymaltose and iron sucrose, both already prescribed to patients suffering from iron deficiency. ${ }^{64}$

\section{Bioreactors and growing erythroid cells at larger scale}

The majority of erythroid cultures described in the literature are small and rely on the use of static tissue plastic flasks. For the reported larger scale cultures, a variety of culture vessels have been utilized. The original $2.5 \mathrm{~mL}$ packed mRBC produced under GMP conditions and tested in a single volunteer were cultured in static plastic flasks. ${ }^{5}$ Spinner flasks (of $1.5 \mathrm{~L}$ and $3 \mathrm{~L}$ volumes) have since been used successfully from day 7 onwards for constantly batch-fed cultures reaching a volume of $\sim 28 \mathrm{~L}$ to produce $10 \mathrm{~mL}$ of packed filtered reticulocytes. ${ }^{6}$ Zhang et al. used rotating wall vessels to grow $2 \times 10^{8}$ cells from cord blood CD $34^{+} \cdot{ }^{13}$ Most recently, Heshusius and colleagues used a 1 L gas-permeable, rapid expansion bioreactor (G-Rex; Wilsonwolf) which, as well as facilitating partial media replenishment, allowed $90 \%$ of the expansion medium to be removed and replaced by differentiation medium. Although the expansion was 10-fold lower in the G-Rex compared to static dishes, the enucleation rate was similar and by extrapolation the authors predicted that $\sim 4.5 \mathrm{~mL}$ mRBC could be produced using this bioreactor. The cell numbers from these studies are encouraging but are still a long way from the prediction by Timmins et al. ${ }^{27}$ who suggested it may be possible to produce 500 units from a single cord blood donation.

There are still many types of bioreactors to choose from and explore further for erythroid culture including: (i) continuous stirred tank bioreactors or spinner flasks which contain internal impellers; (ii) fluidized bed bioreactors in which cells are kept in suspension by the culture medium moving upwards; (iii) rocking heated platforms (wave-like bioreactors) onto which large disposable bags are attached; (iv) rotating wall vessel bioreactors also known as roller bottles and finally, (v) multi-layered static flasks. Whatever becomes the bioreactor of choice for erythroid cell culture, it will need to facilitate higher density culture, be scalable and incorporate automation. In the long term, this will make erythroid culture more cost-effective by: (i) reducing labor costs - cells would be cultured in a single container making the cultures easier to feed and less laborintensive, with the possibility of automated, remote feeding of media and/or specific depleted nutrients; (ii) reducing the footprint and space required for each batch production; (iii) easing scale up; and (iv) minimizing human error and batch-to-batch variation by carefully controlling different parameters (such as $\mathrm{pH}$, agitation and oxygenation) for optimal culture conditions. One can eventually then imagine rooms filled with bioreactors manufacturing $\mathrm{mRBC}$ continuously at scale for clinical use.

The challenge for producing $\mathrm{mRBC}$ in any of the above types of bioreactors type lies in the variety of culture conditions required during this 3 -week process. All cultures are initiated from a small number of HSPC or approximately $100 \times 10^{6}$ PBMNC, seeded in a small volume of medium. The erythroid cells then proliferate reaching a fold expansion of $>10^{5}$ and requiring low cell densities for optimum growth $\left(2-8 \times 10^{5}\right.$ cells $\left./ \mathrm{mL}\right)$ or medium replenishment (constant versus repeated batch feeding). Orthochromatic erythroblasts then enucleate and are relatively fragile during this process. Moreover, erythroid cultures are inherently asynchronous, a proportion of cells start enucleating while others are still proliferating; this is noticeable in the last week of culture. To maximize yield, culture conditions have to support cells at different stages of terminal differentiation and nascent reticulocytes must remain viable until the highest percentage enucleation is reached. A manufacturing process that uses a bioreactor efficiently, minimizing the transitions between different types of culture vessels during the 21 days of culture, producing a high yield of reticulocytes and automating feeding, still needs to be identified.

Once the final product is made (i.e., $\mathrm{mRBC}$ have been filtered and stored), new cultures have to be reinitiated using new donor-derived HSPC. This is where immortalized pluripotent stem cells or an immortalized cell line that enucleates efficiently would be a game-changer as stocks of the same cell phenotype could be maintained.

\section{Reticulocyte filtration and storage}

At the end of the procedure, large-scale erythroid cultures need to be volume reduced and filtered to separate the mRBC from the nucleated cells and expelled nuclei (also known as pyrenocytes). Currently, the filters used are dead-end leukoreduction filters routinely used by blood banks. These have been designed to filter whole blood, which typically consists of $\sim 5 \times 10^{9} \mathrm{RBC}$ and only $\sim 5 \times 10^{6}$ nucleated cells per milliliter of blood. In comparison, the percentage enucleation for $\mathrm{mRBC}$ cultures is approximately $80 \%$ and the medium contains pyrenocytes as well as free DNA released by disintegrated nuclei. It is notable that very few studies on $\mathrm{mRBC}$ yield test the filterability of their final product or report the yield after filtration. This is a key parameter as the mRBC must be purified before clinical use and this process currently alters 
the yield by $30-50 \%$. Strategies and more research are needed to improve reticulocyte recovery after filtration, which will lead to a dramatic increase in yield. There are open-ended filter technologies, such as tangential flow filtration systems or acoustic resonance cell filtration, ${ }^{65}$ which could potentially be used but are as yet untested. More experimental approaches include lab-on-a-chip microfluidic label-free reticulocyte-sorting methods. ${ }^{66}$ All these possibilities need testing and optimizing on a large culture scale which is expensive, therefore, highlighting filtration as a key area of research calling for innovation as well as commercial investment and collaboration.

Once filtered, the $\mathrm{mRBC}$ need to be stored whilst quality control tests are carried out and until they can be transfused into a patient. As reticulocytes, $\mathrm{mRBC}$ are more fragile than $\mathrm{RBC}$ and more optimal storage conditions need to be developed. An alternative approach is to promote maturation of cultured reticulocytes into bona fide erythrocytes, which is another area of active research.

\section{Compliance with Good Manufacturing Practice and quality control}

Finally, it should be remembered that the challenge for $\mathrm{mRBC}$ production is not only to deliver a manufacturing process that can produce enough $\mathrm{mRBC}$ at scale but to develop a process that is GMP-compliant. Often GMP compliance includes the use of clean rooms, highly trained staff specialized in GMP, using closed processes to minimize any risk of infection, robust batch manufacturing protocols, as well as specific manufacturing processing and quality release criteria which are not required in standard R\&D laboratories. The challenges of GMP compliance on large-scale erythroid cultures for a transfusion product may have an impact on yield, add pressure to culture times and increase costs, so will need to be considered and planned for from the outset.

\section{Summary}

Technologies to revolutionize transfusion options for patients with anemia, in particular for those receiving regular life-long transfusions, are much needed. There is great potential for laboratory-grown $\mathrm{mRBC}$ to be used in transfusion practice once production is mastered at scale. In the meantime, these culture systems at smaller scale have proven to be brilliant tools for understanding human erythropoiesis and optimizing culture methodology. The efficient production of $\mathrm{mRBC}$ at scale is now essentially a biotechnological challenge that requires multidisciplinary efforts. We have highlighted some of the key areas, breakthroughs and challenges (summarized in Table 2), in which investment together with intensive research into further optimization of culture systems and use of bioreactors at scale are needed to make the clinical use of adult therapeutic doses of $\mathrm{mRBC}$ become a reality. Focused research and collaboration between academics, blood banks, commercial entities and new spinouts, especially around the use of RBC-based therapeutics, will no doubt help to drive the development and efficiency of $m R B C$ production under GMP conditions into the clinic.

\section{Disclosures}

No conflicts of interest to disclose.

\section{Contributions}

$S P, C E S$ and $A M T$ wrote the review together and all authors approved the final submitted version.

\section{Funding}

$S P, C E S$ and the work in AMT's laboratory is funded in part by a National Institute for Health Research Blood and Transplant Research Unit (IS-BTU-1214-10032) in red blood cell products (University of Bristol) and NHSBT R\&D grants(WP15-05; WP15-04). The views expressed are those of the authors and not necessarily those of the NHS, the NIHR or the Department of Health and Social Care.

\section{References}

1. Tzounakas VL, Valsami SI, Kriebardis AG, Papassideri IS, Seghatchian J, Antonelou $\mathrm{MH}$. Red cell transfusion in paediatric patients with thalassaemia and sickle cell disease: current status, challenges and perspectives. Transfus Apher Sci. 2018;57(3): 347-357.

2. Ware RE, de Montalembert M, Tshilolo L, Abboud MR. Sickle cell disease. Lancet. 2017;390(10091):311-323.

3. Hawksworth J, Satchwell TJ, Meinders M, et al. Enhancement of red blood cell transfusion compatibility using CRISPR-mediated erythroblast gene editing. EMBO Mol Med. 2018;10(6):1-11.

4. Zimring JC, Welniak L, Semple JW, Ness PM, Slichter SJ, Spitalnik SL. Current problems and future directions of transfusioninduced alloimmunization: summary of an NHLBI working group. Transfusion. 2011;51(2):435-441.

5. Giarratana MC, Rouard H, Dumont A, et al. Proof of principle for transfusion of in vitrogenerated red blood cells. Blood. 2011;118(19):5071-5079.
6. Kupzig S, Parsons SF, Curnow E, Anstee DJ, Blair A. Superior survival of ex vivo cultured human reticulocytes following transfusion into mice. Haematologica. 2017;102 (3):476483.

7. Heshusius S, Heideveld E, Burger P, et al. Large-scale in vitro production of red blood cells from human peripheral blood mononuclear cells. Blood Adv. 2019;3(21): 33373350 .

8. Collins AF, Gonçalves-Dias C, Haddad S, et al. Comparison of a transfusion preparation of newly formed red cells and standard washed red cell transfusions in patients with homozygous $\beta$ - thalassemia. Transfusion. 1994;34(6):517-520.

9. Klein HG. Transfusions with young erythrocytes (neocytes) in sickle cell anemia. Am J Pediatr Hematol Oncol. 1982;4(2): 162-165.

10. Sharma DC, Rai S, Agarwal N, Sao S, Gaur A, Sapra R. Transfusion of neocytes concentrate/pooled neocytes in $\beta$-thalassemic patients. Indian J Hematol Blood Transfus. 2008;24(4):173-177.

11. Spanos T, Ladis V, Palamidou F, et al. The impact of neocyte transfusion in the management of thalassaemia. Vox Sang. 1996;70(4):217-223.
12. Triadou P, Girot R, Rebibo D, et al Neocytopheresis: a new approach for the transfusion of patients with thalassaemia major. Eur J Pediatr. 1986;145(1-2):10-13.

13. Zhang Y, Wang C, Wang L, et al. Large-scale ex vivo generation of human red blood cells from cord blood CD34+cells. Stem Cells Transl Med. 2017;6(8):1698-1709.

14. Therapeutics R. Rubius Therapeutics Reports Fourth Quarter and Full-Year 2019 Financial Results and Announces Strategic Focus on Oncology and Autoimmunity. 2020. Available from: https://ir.rubiustx.com/news-releases/newsrelease-details/rubius-therapeutics-reportsfourth-quarter-and-full-year-2019.

15. Trompeter S, Estcourt L, Mora A, et al.The haemoglobinopathy survey: the reality of transfusion practice in sickle cell disease and thalassaemia in England. Transfus Med. 2020;30(6):456-466.

16. Luten M, Roerdinkholder-Stoelwinder B Schaap NP, de Grip WJ, Bos HI, Bosman GJ. Survival of red blood cells after transfusion: a comparison between red cells concentrates of different storage periods. Transfusion. 2008;48(7):1478-1485.

17. Anstee DJ, Gampel A, Toye AM. Ex-vivo 
generation of human red cells for transfusion. Curr Opin Hematol. 2012;19(3):163169.

18. Douay L. Why industrial production of red blood cells from stem cells is essential for tomorrow's blood transfusion. Regen Med. 2018;13(6):627-632.

19. Migliaccio AR, Palis J. Blood in a dish: in vitro synthesis of red blood cells. Drug Discov Today Dis Mech. 2011; 8(1-2):e3-e8

20. Migliaccio AR, Masselli E, Varricchio L, Whitsett C. Ex-vivo expansion of red blood cells: How real for transfusion in humans? Blood Rev. 2012;26(2):81-95.

21. Rousseau GF Mazurier C, Douay L. Culturing red blood cells from stem cells: a solution to present and future challenges of transfusion medicine? ISBT Sci Ser. 2016;11(S1):111-117

22. Severn CE, Toye AM. The challenge of growing enough reticulocytes for transfusion. ISBT Sci Ser. 2018;13(1):80-86.

23. Timmins NE, Nielsen LK. Manufactured $\mathrm{RBC}$ - rivers of blood, or an oasis in the desert? Biotechnol Adv. 2011; 29(6):661-666.

24. Timmins NE, Nielsen LK. Blood cell manufacture: current methods and future challenges. Trends Biotechnol. 2009;27(7):415422 .

25. Rousseau GF, Giarratana MC, Douay L. Large-scale production of red blood cells from stem cells: What are the technical challenges ahead? Biotechnol J. 2014;9(1):28-38.

26. Von Lindern M, Zauner W, Mellitzer G, et al. The glucocorticoid receptor cooperates with the erythropoietin receptor and c-Kit to enhance and sustain proliferation of erythroid progenitors in vitro. Blood. 1999;94 (2):550-559.

27. Timmins NE, Athanasas S, Günther M, Buntine P, Nielsen LK. Ultra-high-yield manufacture of red blood cells from hematopoietic stem cells. Tissue Eng Part C Methods. 2011;17(11):1131-1137

28. Griffiths RE, Kupzig S, Cogan N, et al. Maturing reticulocytes internalize plasma membrane in glycophorin A-containing vesicles that fuse with autophagosomes before exocytosis. Blood. 2012;119(26): 6296-6306

29. van den Akker E, Satchwell TJ, Pellegrin S, Daniels G, Toye AM. The majority of the in vitro erythroid expansion potential resides in CD34(-) cells, outweighing the contribution of CD34(+) cells and significantly increasing the erythroblast yield from peripheral blood samples. Haematologica. 2010; 95(9):1594-1598.

30. Heideveld E, Hampton-O'Neil LA, Cross SJ, et al. Glucocorticoids induce differentiation of monocytes towards macrophages that share functional and phenotypical aspects with erythroblastic island macrophages. Haematologica. 2018;103(3):395-405

31. Heideveld E, Masiello F, Marra M, et al. CD14+ cells from peripheral blood positively regulate hematopoietic stem and progenitor cell survival resulting in increased erythroid yield. Haematologica. 2015;100(11): 1396-1406.

32. Bernecker C, Ackermann M, Lachmann N, et al. Enhanced ex vivo generation of erythroid cells from human induced pluripotent stem cells in a simplified cell culture system with low cytokine support. Stem Cells Dev. 2019;28(23):1540-1551

33. Trakarnsanga K, Griffiths RE, Wilson MC, et al. An immortalized adult human erythroid line facilitates sustainable and scalable generation of functional red cells. Nat
Commun. 2017;8:14750

34. Migliaccio AR, Whitsett C, Migliaccio G. Erythroid cells in vitro: from developmental biology to blood transfusion products. Curr Opin Hematol. 2009;16(4):259-268.

35. Giani FC, Fiorini C, Wakabayashi A, et al Targeted application of human genetic variation can improve red blood cell production from stem cells. Cell Stem Cell. 2016;18(1):73-78

36. Lasho TL, Pardanani A, Tefferi A. LNK mutations in JAK2 mutation-negative erythrocytosis. N Engl J Med. 2010;363(12): 1189-1190.

37. Spolverini A, Pieri L, Guglielmelli P, et al. Infrequent occurrence of mutations in the $\mathrm{PH}$ domain of LNK in patients with JAK2 mutation-negative 'idiopathic' erythrocytosis. Haematologica. 2013;98(9):e101-102.

38. van der Harst P, Zhang W, Mateo Leach I, et al. Seventy-five genetic loci influencing the human red blood cell. Nature. 2012;492 (7429):369-375

39. Thornton N, Karamatic Crew V, Tilley L, et al. Disruption of the tumour-associated EMP3 enhances erythroid proliferation and causes the MAM-negative phenotype. Nat Commun. 2020;11(1):3569

40. Fares I, Chagraoui J, Gareau Y, et al. Cord blood expansion. Pyrimidoindole derivatives are agonists of human hematopoietic stem cell self-renewal. Science. 2014;345 (6203):1509-1512.

41. Boitano AE, Wang J, Romeo R, et al. Aryl hydrocarbon receptor antagonists promote the expansion of human hematopoietic stem cells. Science. 2010;329(5997):1345 1348

42. Zhang CC, Kaba M, Iizuka S, Huynh $\mathrm{H}$ Lodish HF. Angiopoietin-like 5 and IGFBP2 stimulate ex vivo expansion of human cord blood hematopoietic stem cells as assayed by NOD/SCID transplantation. Blood. 2008;111(7):3415-3423.

43. Delaney C, Heimfeld S, Brashem-Stein C, et al. Voorhies H, Manger RL, Bernstein ID. Notch-mediated expansion of human cord blood progenitor cells capable of rapid myeloid reconstitution. Nat Med. 2010;16 (2):232-236.

44. Liu S, Wu $M$, Lancelot $M$, et al. BMI enables extensive expansion of functional erythroblasts from human peripheral blood mononuclear cells. Mol Ther. 2021;29(5): 1918-1932

45. Li Z, Qian P, Shao W, et al. Suppression of $\mathrm{m}(6)$ A reader Ythdf2 promotes hematopoietic stem cell expansion. Cell Res. 2018;28(9):904-917

46. Severn CE, Eissa AM, Langford CR, et al. Ex vivo culture of adult CD34(+) stem cells using functional highly porous polymer scaffolds to establish biomimicry of the bone marrow niche. Biomaterials. 2019, 225:119533.

47. Severn CE, Macedo H, Eagle MJ, Rooney P, Mantalaris A, Toye AM. Polyurethane scaffolds seeded with CD34(+) cells maintain early stem cells whilst also facilitating prolonged egress of haematopoietic progenitors. Sci Rep. 2016;6:32149.

48. Raic A, Rodling L, Kalbacher H, LeeThedieck C. Biomimetic macroporous PEG hydrogels as 3D scaffolds for the multiplication of human hematopoietic stem and progenitor cells. Biomaterials. 2014;35(3): 929 940.

49. Rodling L, Raic A, Lee-Thedieck C. Fabrication of biofunctionalized, cell-laden macroporous 3D PEG hydrogels as bone marrow analogs for the cultivation of human hematopoietic stem and progenito cells. Methods Mol Biol. 2014;1202:121-130.

50. Mortera-Blanco T, Mantalaris A, Bismarck A, Aqel N, Panoskaltsis N. Long-term cytokine-free expansion of cord blood mononuclear cells in three-dimensional scaffolds. Biomaterials. 2011;32(35):9263-9270.

51. Raic A, Naolou T, Mohra A, Chatterjee C, Lee-Thedieck C. 3D models of the bone marrow in health and disease: yesterday, today and tomorrow. MRS Commun. 2019;9(1):37-52

52. Bello AB, Park H, Lee SH. Current approaches in biomaterial-based hematopoietic stem cell niches. Acta Biomater. 2018;72:1-15

53. Wilkinson AC, Ishida R, Kikuchi $M$, et al. Long-term ex vivo haematopoietic-stemcell expansion allows nonconditioned transplantation. Nature. 2019;571(7763) 117-121.

54. Bauer A, Tronche F, Wessely $\mathrm{O}$, et al. The glucocorticoid receptor is required for stress erythropoiesis. Gen Dev. 1999;13(22):29963002

55. Wessely $O$, Deiner EM, Beug $H$, von Lindern $\mathrm{M}$. The glucocorticoid receptor is a key regulator of the decision between self-renewal and differentiation in erythroid progenitors EMBO J. 1997;16(2):267-280.

56. Flygare J, Estrada VR, Shin C, Gupta S, Lodish HF. HIF1 $\alpha$ synergizes with glucocorticoids to promote BFU-E progenitor selfrenewal. Blood. 2011;117(12):3435-3444

57. Narla A, Dutt S, McAuley JR, et al Dexamethasone and lenalidomide have distinct functional effects on erythropoiesis. Blood. 2011;118(8):2296-2304.

58. Huang NJ, Lin YC, Lin CY, et al. Enhanced phosphocholine metabolism is essential for terminal erythropoiesis. Blood. 2018;131 (26):2955-2966

59. Zingariello M, Bardelli C, Sancillo L, et al. Dexamethasone predisposes human erythroblasts toward impaired lipid metabolism and renders their ex vivo expansion highly dependent on plasma lipoproteins. Front Physiol. 2019;10:281.

60. Bernecker C, Köfeler H, Pabst G, et al Cholesterol deficiency causes impaired osmotic stability of cultured red blood cells. Front Physiol. 2019;10:1529.

61. Olivier EN, Zhang S, Yan Z, et al. PSC-RED and MNC-RED: albumin-free and lowtransferrin robust erythroid differentiation protocols to produce human enucleated red blood cells. Exp Hematol. 2019;75:3152.e15.

62. Grillo AS, SantaMaria AM, Kafina MD, et al Restored iron transport by a small molecule promotes absorption and hemoglobinization in animals. Science. 2017;356(6338): 608-616.

63. Aoto M, Iwashita A, Mita K, Ohkubo N, Tsujimoto Y, Mitsuda N. Transferrin receptor 1 is required for enucleation of mouse erythroblasts during terminal differentiation. FEBS Open Bio. 2019;9(2):291-303

64. Geisser P, Burckhardt S. The pharmacokinetics and pharmacodynamics of iron preparations. Pharmaceutics. 2011;3(1):12-33.

65. Trampler F, Sonderhoff SA, Pui PW, et al. Kilburn DG, Piret JM. Acoustic cell filter for high density perfusion culture of hybridoma cells. Biotechnology (N Y). 1994;12(3):281284.

66. Zeming KK, Sato Y, Yin L, et al. Microfluidic label-free bioprocessing of human reticulocytes from erythroid culture. Lab Chip. 2020;20(18):3445-3460 